\title{
Altruism and Global Environmental Taxes
}

\author{
Marc Daube $^{1}$ iD
}

Accepted: 4 September 2018 / Published online: 20 September 2018

(c) The Author(s) 2018

\begin{abstract}
A global externality like the GHG emissions leading to climate change are both due to free-riding at the individual level as well as the government level. A government aiming to maximise domestic social welfare may make individuals internalise the damage within their country, but will free-ride on the damage caused to other countries. Only a global cooperative solution could internalise global damage entirely. If individuals have altruistic concern for others but continue to believe that their consumption is negligible relative to the total, they will not change their behaviour. However, this paper shows that in a multi-country setting the global equilibrium levels of consumption for both the non-cooperative and cooperative solutions are affected by altruism. The key results are (a) that non-cooperative governments maximising domestic welfare will internalise some of the damage inflicted on other countries depending on the level of altruistic concern individuals have, and (b) the cooperative global optimum also changes as altruism leads individuals to effectively experience damage in other countries as well as the direct damage to them. Since altruistic concern for others may vary across countries, global welfare then becomes a function of the relative levels of altruistic concern between countries.
\end{abstract}

Keywords Altruism - Climate change - Environmental economics · Environmental tax · Externalities · Pro-social behaviour · Public goods

JEL Classification Q50 - Q58 · D11 · D90

\section{Introduction}

Climate change resulting from greenhouse gas emissions is a truly global externality, arising from free-riding behaviour both at the individual and government level. Aggregate global emissions cause climate change, and therefore emissions in one country do not just cause a negative externality in that country but also in every other country. At the same time, the damage experienced from climate change may be much more significant in some countries compared to others. Governments can implement an emissions tax to make individuals internalise the economic cost of their consumption causing emissions. Such a tax may reduce

Marc Daube

1 School of Economics and Finance, University of St Andrews, St Andrews, Fife KY16 9AR, Scotland, UK 
emissions to the degree that it maximises the welfare of that country, taking as given the emissions in other countries and the resulting damage for that country, but ignoring the effect of the country's emissions on other countries. While this corrects for individuals' free-riding behaviour within a given country, it is now governments that are free-riding by ignoring the effect the country's emissions have on other countries. And if every country acts that way, such a non-cooperative equilibrium will lead to higher emissions and lower welfare compared to the global cooperative solution where global aggregate welfare is maximised and global damage is fully internalised. For example, Ploeg and Zeeuw (1992) demonstrate this outcome by modelling the Pigovian taxes for a global externality when each country sets their own tax in a non-cooperative way and compare it to the global cooperative solution. ${ }^{1}$ Furthermore, Aronsson and Löfgren (2001) develop a dynamic two-country model of a global externality and evaluate the non-cooperative and cooperative equilibria with regard to valuation problems implicit in environmental accounting.

While we know that in the absence of a global regulator countries have no incentive to cooperate, there are a number of approaches that aim to show how the cooperative global optimum might be achieved nevertheless. For example, Barrett (1990) explores how cooperative agreements might arise in case of global externalities. He first shows that the biggest discrepancies between the cooperative and non-cooperative equilibria arise for global externalities that carry significant damage but are costly to reduce (such as climate change), and also for low damage externalities that can be reduced at relatively low cost. He further summaries a number of approaches that might lead to a cooperative equilibrium, among which is the aspect of morality where governments may be guided by some moral concerns rather than just maximising their countries' welfare. Similarly, Barrett (1994) looks at self-enforcing international agreements, which may either be modelled as members maximising the collective net-benefits or as an infinitely repeated game. He shows that neither approach can sustain full cooperative behaviour when the differences between the net benefits of the global cooperative solution and the non-cooperative solution are large. When looking at international cooperation in climate change policy, it is sometimes thought that if one country leads with climate mitigation measures, others will follow. Game theory dictates that leadership in climate action is generally not successful and will actually lead to a reduction in other countries' efforts. However, Buchholz and Sandler (2017) show that this may be overcome when elements of behavioural models are incorporated, for example when the follower country has non-selfish preferences or the leader's actions have an influence on the follower's belief about the leader's behaviour.

Furthermore, while emission permit based mechanisms, such as used in the Kyoto protocol, are deemed to be of limited potential to establish sufficient international cooperation, there are other proposals, for example the price influencing climate protection scheme put forward by Nordhaus (2006). ${ }^{2}$ Altemeyer-Bartscher et al. (2010) further develop this approach by proposing a scheme that includes side-payments. The literature also points to the importance of measuring and considering the ancillary benefits of climate protection because regional secondary benefits of climate protection efforts may overcome free-riding behaviour (e.g. Markandya and Rübbelke 2004), and in particular in conjunction with side-payments or tax transfers (e.g. Altemeyer-Bartscher et al. 2011; Markandya and Rübbelke 2012; Altemeyer-

\footnotetext{
1 They start with a simple static model with flow pollution but the bulk of the analysis focusses on a dynamic approach with stock pollution.

2 This is "essentially a dynamic Pigovian pollution tax" (p. 32).
} 
Bartscher et al. 2014). ${ }^{3}$ Other contributions in the area of global externalities and taxation ${ }^{4}$ evaluate the effects of labour mobility (e.g. Aronsson and Blomquist 2003; Bierbrauer et al. 2013), ${ }^{5}$ non-competitive markets (e.g. Tahvonen 1995), Veblen effects (e.g. Aronsson and Johansson-Stenman 2014, 2015), ${ }^{6}$ and the existence of abatement activities that only mitigate local pollution in addition to those that mitigate global pollution (e.g. Pittel and Rübbelke 2017).

The potential for free-riding at the government level is of course a result of free-riding at the individual level. This paper aims to combine the issues of free-riding at the individual level and at the country level with the concept that individuals may exhibit altruistic concern for others, in their own country and in other countries. Altruism in the form where an individual's utility is to some degree a function of others' utility, but not a specific component of it, is generally referred to as Pure Altruism. ${ }^{7}$ Applications of this type of altruism are often used in smaller environments such as the family where one might care about the welfare of specific individuals (for example Becker 1974, 1981). In large-scale contexts it can also be assumed that an individual cares for the total or average welfare of all other individuals in the population (e.g. Johansson 1997; Daube and Ulph 2016). The model developed in this paper is closely linked to the model setup used in Daube and Ulph (2016) and extends their static model of Pure Altruism to a setting of multiple countries. Their model demonstrates that as long as individuals continue to believe that total emissions are unaffected by their consumption choice, then no matter how much they care about the welfare of others, their behaviour will not change. ${ }^{8}$ Furthermore, it shows in a single country context that the optimal tax is still the standard Pigovian tax equal to social marginal damage. Daube and Ulph (2016) start with a model of Pure Altruism, but its main contribution from there is the development of an alternative theory of behaviour where individuals do not necessarily act in a utilitymaximising way, but may base their consumption decision on a hypothetical moral benefit determined by asking what would be optimal if they and everybody else were to make the same choice. ${ }^{9}$

\footnotetext{
3 The relevance of ancillary benefits goes back to the analysis of impure public goods first put forward by Cornes and Sandler (1984) who showed that joint production of public and private goods may reduce the problem of under-provision of the public good.

4 The theory on international tax competition and coordination between countries is an issue that has direct significance for the development of environmental taxes as well. Keen and Konrad (2013) provide for a thorough introduction on this topic.

5 Aronsson and Blomquist (2003) model optimal tax policy for trans-boundary environmental problems with labour mobility. Using a two-type approach they show that ability has an impact on the optimal tax, but even with labour mobility part of the externality remains uninternalised in a non-cooperative equilibrium. Only a cooperative approach can fully internalise the externality. Bierbrauer et al. (2013) look at tax competition with perfect labour mobility when skills are unobservable and show that the race-to-the-bottom problem also holds in this setting.

6 Aronsson and Johansson-Stenman (2014) analyse the optimal provision of both national and global public goods when individuals care about relative consumption levels, both relative to others in their country as well as relative to individuals in other countries, but do not address the issue of taxation. Aronsson and JohanssonStenman (2015) take this forward by looking at the same care about relative consumption, but in relation to optimal income taxation. They find that when tax policy is set by competing governments then they only internalise the externality arising from the comparison within the country, but a Stackelberg leader will also reflects between-country effects to some degree.

7 Paternalistic Altruism, on the other hand, means that an individual's utility is not a function of others' utility as such, but a specific component of that utility (see Archibald and Donaldson 1976). In an environmental context, this component may be the damage others experience from the dirty good.

8 This result is also consistent with the analysis of Johansson (1997) for large populations.

9 Daube and Ulph (2016) also contains a detailed overview on the literature of altruism and self-image effects.
} 
The model in this paper will first be developed under standard theory with self-interested individuals only, and then add individuals' altruistic concern for the utility of others. Individuals in any given country may exhibit a different level of altruistic concern for the total utility in their own country compared to the concern for total utility in other countries. Indeed, individuals can have different levels of altruistic concern for every country. Intuitively, it is plausible to assume that an individual may care more for the well-being of the people in their own country, or people closer to the individual, compared to individuals who may live half way around the world. The analysis starts from individual behaviour but focusses mostly on socially optimal levels of consumption under the non-cooperative solution where governments individually aim to maximise their country's welfare, and compares it to the cooperative solution where global welfare is maximised. This paper makes no efforts to show how such a global equilibrium may be achieved but simply compares the consumption levels under those different equilibria. The main results are:

- Individuals' altruistic concern for the welfare of others (Pure Altruism) will alter the non-cooperative equilibrium resulting from domestic social planners and lead countries to internalise some, but not all, of the damage caused by emissions in their country, depending on the level of altruistic concern relative to the concern for themselves and others in their country.

- However, altruistic concern will also alter the welfare-maximising global optimum, requiring a lower level of emissions as individuals effectively experience damage from the externality through

1. the direct effect of their country's damage function on personal welfare, and

2. the effect of altruistic concern and thus the damage individuals in other countries experience from the externality.

- Since socially optimal consumption in the global optimum then depends on the relative levels of altruistic concern, the degree to which damage is internalised in each country will now differ across countries and thus there is no single global tax rate to achieve the optimum, contrary to the case of standard theory.

- In a non-cooperative equilibrium of two countries a population increase in one country may either increase or decrease equilibrium consumption in another country, depending on the relative size of the countries (with and without altruism).

The paper will proceed as follows. Section 2 describes the basic model setup. Section 3 will then develop the general model and evaluate the results under standard theory. This serves as counterfactual to the analysis with Pure Altruism in Sect. 4. Section 5 will then look at comparative statics analysis with respect to population sizes, before Sect. 6 provides some concluding remarks and presents ideas for potential further research.

\section{Model Setup}

We start with a continuum of individuals living in $n$ discrete countries. Individuals within a given country have the same initial endowment of income $y_{i}>0$, where $1 \leq i \leq n$. An individual chooses consumption levels of a clean $\operatorname{good} x$ and a dirty good $z$, where the clean good is a numeraire good with a price of 1 , and therefore represents expenditure on all other goods but the dirty good. Consumption of the clean good generates no externalities. The dirty good, however, generates one unit of emissions per unit of consumption, which is a negative externality to all individuals across all countries. The average consumption of the dirty good 
within country $i$ is denoted by $\bar{z}_{i}$. The size of the population of each country $i$ is measured by $M_{i}$. Therefore total emissions in country $i$ are captured by

$$
E_{i}=M_{i} \bar{z}_{i}
$$

Furthermore, aggregate global emissions are simply the sum of the total emissions in each country, or formally

$$
E_{T}=\sum_{i=1}^{n} E_{i}=M_{T} \bar{z}_{T}
$$

where $M_{T}$ measures the global population size and $\bar{z}_{T}$ captures global average consumption of the dirty good.

The damage individuals in country $i$ experience from the negative emissions externality of the dirty good is captured by the damage functions $D_{i}\left(E_{T}\right)$. A key component of this multi-country model is that each country can experience different damage as a result of the emissions externality and we have $n$ different damage functions. Therefore this setup also captures any ancillary costs of the emissions externality that are local to a particular country. Note that the damage function is a function of $E_{T}$, and therefore it is always total global emissions that determine the damage experienced. ${ }^{10}$ Different countries may suffer differently from those total emissions (i.e. different countries may have different damage functions), but emissions in each country contribute equally to global emissions and every country's experienced damage is a consequence of the same total emissions. As such we are modelling a truly global pollutant, in line with the aim of capturing some of the distinguishing features of climate change. Formally, damage experienced by individuals in country $i$ is given by

$$
D_{i}\left(E_{T}\right)=D_{i}\left(M_{T} \bar{z}_{T}\right)=D_{i}\left(\sum_{i=1}^{n} M_{i} \bar{z}_{i}\right) \quad \forall 1 \leq i \leq n
$$

where $M_{T}=\sum_{i=1}^{n} M_{i}$ and $\bar{z}_{T}=\frac{1}{M_{T}} \sum_{i=1}^{n} M_{i} \bar{z}_{i}$. Furthermore we have the global damage function

$$
D_{T}\left(E_{T}\right)=\frac{1}{M_{T}} \sum_{i=1}^{n} M_{i} D_{i}\left(E_{T}\right), \quad \text { where } D_{T}^{\prime}\left(E_{T}\right)>0, D_{T}^{\prime \prime}\left(E_{T}\right)>0, \quad \forall \quad E_{T}>0 .
$$

From this it is also straightforward to derive that

$$
\frac{\partial D_{T}\left(E_{T}\right)}{\partial z_{i}}=\frac{M_{i}}{M_{T}} \sum_{i=1}^{n} M_{i} D_{i}^{\prime}\left(E_{T}\right) \quad \forall 1 \leq i \leq n,
$$

and

$$
M_{T} D_{T}^{\prime}\left(E_{T}\right)=\sum_{i=1}^{n} M_{i} D_{i}^{\prime}\left(E_{T}\right)
$$

${ }^{10}$ In a different setting one could also model that emissions generated in a particular country cause more damage in that country and only a fraction of the emissions generated in other countries enter the damage function for that country. For example, damage in country $i$ could be given by the function $D_{i}\left(E_{i}+\theta_{i} \sum_{j \neq i} E_{j}\right)$. 

by

Given the above, we can now define the utility derived from consumption of the two goods

$$
u_{i}\left(x_{i}, z_{i} ; E_{T}\right)=x_{i}+\phi_{i}\left(z_{i}\right)-D_{i}\left(E_{T}\right) \quad \forall 1 \leq i \leq n,
$$

where

$$
\phi_{i}^{\prime}\left(z_{i}\right)>0, \phi_{i}^{\prime \prime}\left(z_{i}\right)<0 ; \quad \text { and } \quad D_{i}^{\prime}\left(E_{T}\right)>0, D_{i}^{\prime \prime}\left(E_{T}\right)>0, \quad \forall \quad E_{T}>0, \quad 1 \leq i \leq n .
$$

Damage experienced from the emissions externality is a strictly increasing and strictly convex function of total global emissions for all positive levels of emissions. The private gross benefit derived by individuals in country $i$ from consumption of the dirty good is captured by $\phi_{i}\left(z_{i}\right)$ and is a strictly increasing and strictly concave function of consumption of the dirty good $z_{i}$. The dirty good is produced with constant unit $\operatorname{cost} c_{i}>0$, which again is the same for individuals within country $i$ but may differ across countries. In addition, governments of the different countries impose an emissions tax $t_{i} \geq 0$ on consumption of $z_{i}$. However, in each country this tax revenue is redistributed to the individuals through a lump-sum transfer $\sigma_{i}$ which is identical for all individuals in country $i$. The government budget constraint for country $i$ is therefore defined by

$$
\sigma_{i}=t_{i} \bar{z}_{i}, \quad \forall 1 \leq i \leq n .
$$

\section{Standard Theory}

We can now develop the model under standard theory, where individuals simply maximise their own private utility of consumption without any altruistic concern for the utility of others.

\subsection{Individual Behaviour}

As shown in (1), individuals derive private utility from consumption of the two goods through a quasi-linear utility function. Specifically, utility is linear in consumption of the clean good. This ensures there are no issues of income distribution and welfare losses that may arise are not due to inequality but inefficiencies. Furthermore, and also for simplicity, the utility function assumes that individuals within a given country have the same preferences over the two goods and therefore individuals within each country have identical utility functions. However, preferences over the two goods may differ across countries. ${ }^{11}$

Given the definition of the government budget constraint in (2), the individual's private utility can be expressed as

$$
u_{i}\left(z_{i} ; \bar{z}_{i}, \bar{z}_{T}, t_{i}\right)=\left(y_{i}+t_{i} \bar{z}_{i}\right)-\left(c_{i}+t_{i}\right) z_{i}+\phi_{i}\left(z_{i}\right)-D_{i}\left(E_{T}\right) \quad \forall 1 \leq i \leq n .
$$

A key feature of this model is the atomistic nature of the consumption choice, formally captured by the continuum of individuals. This means that the individual's consumption choice has no impact on total emissions and the damage experienced, as well as no impact on the government budget constraint. The consequence of those two fundamental assumptions

\footnotetext{
11 The model could be developed such that preferences differ within each country, but this would make the analysis more complex without adding to the key theme addressed in this paper. Rather than saying that all individuals in a given country actually have identical preferences, one could think of the utility function as a representative average function for that country.
} 
is that individuals take total global emissions, and therefore the damage experienced from the emissions externality, as given. An individual in country $i$ will choose their consumption of the dirty good by maximising their utility shown in (3). Using the first order condition it is then straightforward to show that the consumption choice for an individual in country $i$, denoted by $\tilde{z}_{i}(t)$, is characterised by ${ }^{12}$

$$
\phi_{i}^{\prime}\left[\tilde{z}_{i}(t)\right]=c_{i}+t_{i} \quad \forall 1 \leq i \leq n .
$$

The left hand side of (4) describes the marginal private gross benefit from consumption of the dirty good while the right hand side describes the private marginal cost. Indeed this is the same result as in Daube and Ulph (2016), the only difference being that individuals in different countries may have different private preferences over consumption of the dirty good, may be subject to differences in the production cost of the dirty good, and have their government impose a different tax on the dirty good.

\subsection{Domestic Social Planner}

We have two possible approaches for the social welfare functions. The first is the noncooperative approach where governments aim to maximise total welfare for their country only (taking consumption in all other countries as given). This will be called the 'Domestic Planner' approach. The second approach is the cooperative global solution where global welfare (i.e. the sum of all countries' welfare functions) is maximised. This is labelled 'Global Planner'.

We start by looking at the optimal level of consumption from the Domestic Planner's perspective. For this let us first define $\bar{z}_{-i}=\sum_{j \neq i} \bar{z}_{j}$ and $M_{-i} \bar{z}_{-i}=\sum_{j \neq i} M_{j} \bar{z}_{j}$, which captures the total consumption of the dirty good across all countries other than country $i$. Because individuals in country $i$ have identical and strictly concave utility functions, everybody in country $i$ consumes the same amount of the dirty good in the domestic optimum. Therefore country $i$ 's social utility function is given by

$$
S_{i}\left(z_{i} ; \bar{z}_{-i}\right)=y_{i}-c_{i} z_{i}+\phi_{i}\left(z_{i}\right)-D_{i}\left(M_{i} z_{i}+M_{-i} \bar{z}_{-i}\right) \quad \forall \quad 1 \leq i \leq n .
$$

The Domestic Planner takes into account the link between the taxes paid on the dirty good and the lump-sum transfer individuals receive through the government budget constraint. This means the socially optimal level of consumption is independent of the tax rate. Furthermore, the Domestic Planner also takes account of the connection between consumption of the dirty good in country $i$ and global emissions $E_{T}$. However, in the multi-country context the Domestic Planner also has to take into account consumption of the dirty good in all other countries because the damage experienced in country $i$ is a function of global emissions which is in turn determined by the consumption of the dirty good in each of the $n$ countries. Since we are dealing with a non-cooperative situation, the standard Nash assumption where the planner takes consumption in all other countries as given applies. The optimal level of consumption in country $i$ from the Domestic Planner's perspective, denoted by $\hat{z}_{i}^{D}$, is therefore defined by

$$
\phi_{i}^{\prime}\left(\hat{z}_{i}^{D}\right)=c_{i}+M_{i} D_{i}^{\prime}\left(M_{i} \hat{z}_{i}^{D}+M_{-i} \bar{z}_{-i}\right) \quad \forall 1 \leq i \leq n .
$$

12 Here and subsequently all the relevant second-order conditions are assumed to hold. 
The above shows that the socially optimal level is achieved when the private marginal gross benefit of consumption is equal to the social marginal cost of consumption in country $i$. This characterisation of the socially optimal level of consumption is similar to that of the single country model developed by Daube and Ulph (2016). The characterisation fully internalises the damage experienced in country $i$ and takes full account of the government budget constraint and the redistribution of the tax revenues. However, since the Domestic Planner optimises only domestic welfare, this socially optimal level ignores the effect of consumption in country $i$ on the damage experienced in other countries. This is of course an illustration of the free-riding behaviour countries may engage in by ignoring the effects of their actions on other countries. ${ }^{13}$

Result 1 In a multi-country setting a domestic social planner will free-ride on the damage caused by consumption in their country but experienced in the other countries.

This result is similar to Ploeg and Zeeuw (1992), although their model has identical damage functions for all countries. Now, by comparing (4) and (6) it is straightforward to see that the optimal tax on the dirty good in country $i$ inducing everyone in country $i$ to consume the socially optimal level is

$$
\hat{t}_{i}^{D}=M_{i} D_{i}^{\prime}\left(M_{i} \hat{z}_{i}^{D}+M_{-i} \bar{z}_{-i}\right) \quad \forall 1 \leq i \leq n .
$$

\subsection{Global Social Planner}

In contrast to the Domestic Planner a Global Social Planner aims to maximise global welfare across all $n$ countries. This global welfare function consists of the sum of all countries' social welfare functions and is therefore given by

$$
S_{T}\left(z_{1}, \ldots, z_{n}\right)=\sum_{i=1}^{n}\left\{M_{i}\left[y_{i}-c_{i} z_{i}+\phi_{i}\left(z_{i}\right)-D_{i}\left(M_{1} z_{1}+\cdots+M_{n} z_{n}\right)\right]\right\} .
$$

In the case of the Domestic Planner each country took consumption in every other country as given. However, the Global Planner maximises aggregate welfare and therefore simultaneously chooses the globally optimal consumption level of the dirty good for each of the $n$ countries. This cooperative global optimum for country $i$ is characterised by

$$
\begin{aligned}
\phi_{i}^{\prime}\left(\hat{z}_{i}^{G}\right) & =c_{i}+\sum_{j=1}^{n} M_{j} D_{j}^{\prime}\left(M_{1} \hat{z}_{1}^{G}+\cdots+M_{n} \hat{z}_{n}^{G}\right) \\
& =c_{i}+M_{T} D_{T}^{\prime}\left(M_{1} \hat{z}_{1}^{G}+\cdots+M_{n} \hat{z}_{n}^{G}\right) \quad \forall \quad 1 \leq i \leq n .
\end{aligned}
$$

Contrary to the case of the Domestic Planner, (9) shows that in a global equilibrium global damage of consumption of the dirty good is fully internalised in each country. This means that consumption in country $i$ does not just internalise the damage experienced in country $i$, but also the damage in all other countries. It also means that if preferences over the dirty good and the cost of production were the same for each country $\left(\phi(z)=\phi_{i}(z)\right.$ and $c=c_{i}$, $\forall 1 \leq i \leq n)$, then we would have the same level of optimal consumption in each of the

\footnotetext{
13 Note that if the damage function in country $i$ were linear in total global emissions $E$, then marginal damage would be constant and therefore marginal damage would be independent of consumption in other countries. In that case both the socially optimal consumption level and the corresponding optimal tax on the dirty good would be independent of consumption elsewhere.
} 
$n$ countries. It is important to note that it would be the same level of consumption for each country regardless of their size or damage function. This is because global damage is now equally distributed across all individuals globally and each individual carries an equal share of global damage. The global optimum is driven by global marginal damage rather than the damage experienced in each country. A key factor for this result is the assumption that it is total global emissions that cause the damage experienced in each country. Note that if only a fraction of the emissions caused in other countries would contribute to the damage experienced in country $i$ (as mentioned in Sect. 2), then the global optimum would not internalise global emissions equally, but country $i$ would only internalise other countries' emissions to the extent that they spill over to other countries.

Furthermore, it is noteworthy that in the global social optimum consumption in country $i$ internalises the damage experienced in country $i$ as a result of a consumption change in country $i$ as well as the damage experienced in country $j$ as a result of a consumption change in country $j$, which is why it equates to internalising global damage. To illustrate this point, let us look at a simplified case with two countries. Then the global social optimum for country 1 is characterised by

$$
\phi_{1}^{\prime}\left(\hat{z}_{1}^{G}\right)=c_{1}+M_{1} D_{1}^{\prime}\left(M_{1} \hat{z}_{1}^{G}+M_{2} \hat{z}_{2}^{G}\right)+M_{2} D_{2}^{\prime}\left(M_{1} \hat{z}_{1}^{G}+M_{2} \hat{z}_{2}^{G}\right) .
$$

The last part of this is the marginal damage experienced in country 2 as a result of a marginal increase of average consumption in country 2 . However, this is not the same as the marginal damage experienced in country 2 as a result of a marginal increase in consumption in country 1 , which would capture the damage inflicted by country 1 on country 2 . Yet, we can also rewrite (10) as

$$
\phi_{1}^{\prime}\left(\hat{z}_{1}^{G}\right)=c_{1}+M_{1} D_{1}^{\prime}\left(M_{1} \hat{z}_{1}^{G}+M_{2} \hat{z}_{2}^{G}\right)+\frac{M_{2}}{M_{1}} M_{1} D_{2}^{\prime}\left(M_{1} \hat{z}_{1}^{G}+M_{2} \hat{z}_{2}^{G}\right) .
$$

Then we see that the global optimum internalises the damage inflicted by country 1 on country 2 , adjusted for the relative population sizes. Intuitively this is the case because the Global Planner optimises the joint welfare functions across both countries, which is of course weighted by the different population sizes and thus even a global optimum does not necessarily require that the damage inflicted on another country is fully internalised within one country, but the Global Planner is able to distribute the degree of internalisation such that global welfare is maximised by each country internalising global damage caused by consumption of the dirty good across all countries.

Result 2 A global social planner fully internalises global damage and ensures that each individual carries an equal share of global damage. If private preferences over the dirty good and the cost of production of the dirty good are the same for all individuals globally (i.e. $\phi(z)=\phi_{i}(z)$ and $c=c_{i} \forall 1 \leq i \leq n$ ), then all individuals will consume the same amount of the dirty good under the global social optimum regardless of the countries' population sizes and damage experienced from the externality.

Comparing (4) and (9), it is then straightforward to see that the global optimum can be achieved by a single tax rate imposed on each country. This globally optimal tax on the dirty good is equal to global marginal damage, or

$$
\hat{t}_{i}=\hat{t}=M_{T} D_{T}^{\prime}\left(M_{1} \hat{z}_{1}^{G}+\cdots+M_{n} \hat{z}_{n}^{G}\right) \quad \forall 1 \leq i \leq n .
$$

This is an important result because if a cooperative solution could be achieved, the optimum could be induced through a single tax rate on the dirty good for all countries. This would 
not just be simpler to implement in practice, it also is a fair solution since it imposes the same tax on each individual globally while consumption can still differ in line with private preferences over the dirty good.

Result 3 The global social optimum can be achieved by a single tax on the dirty good applied to each country, equal to global marginal damage of consumption of the dirty good.

After having developed the model under standard theory we can now begin to explore how these results change when individuals exhibit altruistic concern for the utility of others.

\section{Pure Altruism}

This paper uses Pure Altruism in the sense that individuals' utility is a function of the direct utility of all other individuals in the population rather than just specific individuals. ${ }^{14}$ However, given the multi-country setup, the individual can have a different level of altruistic concern for others' utility in their country compared to others' utility in other countries. Indeed, the individual may have a different level of altruistic concern for each of the $n$ countries. The degree of altruistic concern of individuals in country $i$ for an individual in country $i$ is captured by the parameter $\alpha_{i i} \geq 0$, while altruistic concern of individuals in country $i$ for an individual in country $j$ is captured by $\alpha_{i j} \geq 0 .{ }^{15}$ Therefore the total level of altruistic concern an individual in country $i$ has for the whole population of country $i$ is given by $\alpha_{i i} M_{i}$, and similarly the total level of altruistic concern an individual in country $i$ has for the whole population of country $j$ is given by $\alpha_{i j} M_{j}$. Since the degree of altruism is defined as the degree of care for an individual, and the degree of altruism is assumed to be equal for all individuals in that country, the total weight of altruistic concern is greater the larger the population, given a fixed level of $\alpha$. This reflects the idea that while an individual could have a very high level of altruistic concern for individuals in a very small country, this will be offset to some degree by the fact that a large amount of people are affected by the emissions externality in another country, even though the concern for each individual may be lower. Furthermore, in order to maintain the reasonable assumption that the individual cares at least as much for their private utility from consumption as for the utility of all others, we further require that

$$
0 \leq \sum_{j=1}^{n} M_{j} \alpha_{i j} \leq 1 \quad \forall 1 \leq i \leq n .
$$

As will become evident, this assumption is crucial to the interpretation of the results. The condition above effectively ensures that the welfare derived directly from consumption of the dirty good does not become negligible compared to the welfare derived from altruistic concern for others. ${ }^{16}$ Also note that for simplicity this paper assumes that all individuals in any particular country have the same levels of altruistic concern, but altruistic concern between countries is of course allowed to differ.

\footnotetext{
14 See for example Johansson (1997) and Hammond (1987).

15 Note that the altruism parameter is assumed to be non-negative since a negative $\alpha$ would not capture a degree of altruism but rather some type of 'Schadenfreude'.

16 This approach is consistent with the same argument made in Johansson (1997).
} 


\subsection{Individual Behaviour}

This section will refer to an individual's utility function that includes utility derived from altruistic concern as the individual's 'welfare'. ${ }^{17}$ An individual's personal welfare is given by the sum of their direct utility of consumption and the total utility of all other individuals weighted by the corresponding degrees of altruistic concern, $\alpha_{i j}$. Therefore we have

$$
\begin{aligned}
w_{i}\left(z_{i} ; \bar{z}_{i}, t_{i}, \alpha_{i j}\right)= & \left(y_{i}+t_{i} \bar{z}_{i}\right)-\left(c_{i}+t_{i}\right) z_{i}+\phi_{i}\left(z_{i}\right)-D_{i}\left(M_{T} \bar{z}_{T}\right) \\
& +\sum_{j=1}^{n} \alpha_{i j} M_{j} \bar{u}_{j}(.) \quad \forall 1 \leq i \leq n,
\end{aligned}
$$

where $\bar{u}_{j}($.$) captures the average personal utility of individuals in country j$. Note that individuals have altruistic concern for the direct utility derived from their consumption choice, but no altruistic concern for the indirect utility others derive from their altruistic concern. This is done to avoid a loop effect where one individual would be affected by another's altruistic concern for that individual. From (14) it is straightforward to determine that due to the atomistic nature of consumption, the individual's consumption choice has no impact on the utility of others, neither in their own country nor in any other country, and therefore the individual's consumption choice is still characterised by (4). Thus altruism has no effect on an individual's consumption choice. However, it may affect the socially optimal levels of consumption as we will determine in the next section. Just as we did for standard theory we will look at two cases of social welfare optimisation, under a Domestic Planner and under a Global Planner.

\subsection{Domestic Social Planner}

The Domestic Planner maximises total welfare in their country. We assume that total welfare is simply the sum of all individuals' welfare including the effects of altruistic concern for others. Therefore the social welfare function for a Domestic Planner is given by

$$
\begin{aligned}
W_{i}\left(z_{i}, \alpha_{i j}\right)= & S_{i}(.)+\sum_{j=1}^{n}\left\{\alpha_{i j} M_{j} S_{j}(.)\right\} \\
= & \left(1+\alpha_{i i} M_{i}\right) S_{i}(.)+\sum_{j \neq i}\left\{\alpha_{i j} M_{j} S_{j}(.)\right\} \\
= & \left(1+\alpha_{i i} M_{i}\right)\left[y_{i}-c z_{i}+\phi\left(z_{i}\right)-D_{i}\left(M_{i} z_{i}+M_{-i} \bar{z}_{-i}\right)\right] \\
& +\sum_{j \neq i}\left\{\alpha_{i j} M_{j}\left[\left(y+t_{j} \bar{z}_{j}\right)-\left(c+t_{j}\right) \bar{z}_{j}+\phi\left(\bar{z}_{j}\right)-D_{j}\left(M_{i} z_{i}+M_{-i} \bar{z}_{-i}\right)\right]\right\} \\
& \forall 1 \leq i \leq n .
\end{aligned}
$$

We still have identical personal welfare functions for all individuals in country $i$ and therefore in the domestic optimum, each individual in country $i$ will consume the same amount of the dirty good. Maximising the social welfare function we find that the domestically

17 This is of course a personal welfare function rather than a social welfare function. 
optimal level of consumption of the dirty good is characterised by

$$
\begin{aligned}
\phi_{i}^{\prime}\left(\hat{z}_{i}^{D}\right)= & c_{i}+M_{i} D_{i}^{\prime}\left(M_{i} \hat{z}_{i}+M_{-i} \bar{z}_{-i}\right) \\
& +\sum_{j \neq i}\left\{\frac{\alpha_{i j} M_{j}}{1+\alpha_{i i} M_{i}} M_{i} D_{j}^{\prime}\left(M_{i} \hat{z}_{i}+M_{-i} \bar{z}_{-i}\right)\right\} \quad \forall \quad 1 \leq i \leq n .
\end{aligned}
$$

The above characterises the reaction function for each country analogous to those in Sect. 3.2 leading to the non-cooperative Nash Equilibrium. Daube and Ulph (2016) found that in the single country setting the level of altruistic concern for the utility of others has no impact on the socially optimal level of consumption. However, from (16) we see that altruism does affect the domestic optimum in a multi-country setting. Taking a closer look we can see that the degree to which the damage experienced in country $i$ is internalised is independent of the level of altruistic concern individuals in country $i$ may have for others in their country. This is consistent with the results of the model in Daube and Ulph (2016). However, we also see that the degree to which damage experienced in the other countries as the result of consumption in country $i$ is internalised by the Domestic Planner is driven by the relative levels of altruistic concern. The key factor in this multi-country setting is that the chosen level of consumption by the Domestic Planner affects total emissions and thus also has an impact on the damage experienced in the other country, which in turn has an impact on domestic welfare driven by their level of altruistic concern for other countries' welfare.

To clarify this, note that if individuals in country $i$ did not have any altruistic concern for the individuals in any other country (i.e. if $\alpha_{i j}=0 \forall j \neq i$ ), then this would be the same as under standard theory shown in (6). However, since individuals may have altruistic concern for individuals in the other countries (potentially a different level for each country), the damage experienced in country $j \neq i$, but caused as a result of consumption in country $i$, now also enters the socially optimally level of consumption in country $i$. Furthermore, note that the degree to which this influences the domestic optimum is not simply a function of the altruistic concern for the other country, but the level of altruistic concern for the other country relative to the concern for their own private utility and altruistic concern for their own country. This means that the lower the altruistic concern for the other country compared to the concern for their own country, the less of the damage caused to other countries will be internalised.

To get a clearer picture of how exactly the level of altruistic concern influences the domestic optimum it is helpful to look at the simpler case of just two countries. Then the equivalent of (16) for the optimal consumption in country 1 with a Domestic Planner in country 1 becomes

$$
\phi_{1}^{\prime}\left(\hat{z}_{1}^{D}\right)=c_{1}+M_{1} D_{i}^{\prime}\left(M_{1} \hat{z}_{1}+M_{2} \bar{z}_{2}\right)+\frac{\alpha_{12} M_{2}}{1+\alpha_{11} M_{1}} M_{1} D_{2}^{\prime}\left(M_{1} \hat{z}_{1}+M_{2} \bar{z}_{2}\right) .
$$

The coefficient $\frac{\alpha_{12} M_{2}}{1+\alpha_{11} M_{1}}$ determines to what degree the damage inflicted on country 2 is internalised, and captures the level of altruistic concern for country 2 relative to the total weight given to the individual's private utility of consumption (equal one) and their altruistic concern for all other individuals in country 1.

Due to the constraint on the total level of altruistic concern relative to the private utility of consumption as defined in (13), which is $\alpha_{11} M_{1}+\alpha_{12} M_{2} \leq 1$ in the two country case, and assuming that there is at least some degree of altruistic concern for domestic welfare if there is concern for the other country (i.e. $\alpha_{11}>0$ if $\alpha_{12}>0$ ), then we know that $\frac{\alpha_{12} M_{2}}{1+\alpha_{11} M_{1}}<1$. Therefore the Domestic Planner will never fully internalise the damage caused by consumption in country 1 but experienced in country 2 . The only way for the damage to be fully internalised is if there were no domestic altruism $\left(\alpha_{11}=0\right)$ while at the same time 
having the maximum level of altruistic concern for the other country $\left(\alpha_{12} M_{2}=1\right)$. However, this special case could only occur in the case of two countries. When there are more than two countries, none of the coefficients could be equal to one. We can therefore generalise this result to the $n$-country case and say that for $n>2$ the Domestic Planner will never fully internalise the damage imposed on any other country caused by consumption in their country, regardless of the level of altruistic concern (given the conditions imposed on the size of altruistic concern). While, unlike in the single country model, the level of altruism does matter to the Domestic Planner, and the impact of consumption on damage experienced in other countries is internalised to some degree, it is not fully internalised.

Result 4 In a multi-country setting altruistic concern for the welfare of individuals in another country is necessary for a Domestic Planner to internalise to some degree the damage inflicted on another country as a result of domestic consumption. The degree to which damage in other countries is internalised depends on the altruistic concern for the other country relative to the concern for the individuals direct utility and the welfare of others in that country. However, for any $n>2$ the Domestic Planner will never fully internalise the damage inflicted on another country, regardless of the levels of altruistic concern, given the constraints on the levels of altruistic concern as defined in (13).

From (16) we can also derive that $\frac{\partial \hat{z}_{i}^{D}}{\partial \alpha_{i j}}<0 \forall 1 \leq i, j \leq n$, where $i \neq j$. This makes intuitive sense. As the degree of altruistic concern increases relative to the concern for their own country, individuals will internalise more of the other countries' damage and the resulting equilibrium level of consumption will be lower. Similarly, we find that $\frac{\partial \hat{z}_{i}^{D}}{\partial \alpha_{i i}}>0 \forall 1 \leq$ $i \leq n$. An increase in the altruistic concern for the utility of their own country lowers the relative importance of the damage experienced in other countries and therefore country $i$ can consume more under the domestic equilibrium. Here it is of course important to keep in mind that a decrease in the country $i$ 's consumption will also have an effect on the equilibrium consumption in all other countries. Furthermore, as we have established in detail in Sect. 3.2, the Nash Equilibrium level of consumption under the Domestic Planner is a function of the relative population sizes and damage experienced in the other countries, regardless whether there is altruistic concern or not. ${ }^{18}$

So far we have looked at this social optimum as internalising the damage inflicted on another country. However, we can also evaluate whether the levels of altruistic concern could be sufficient to induce a Domestic Planner to internalise global damage. To investigate this we start by rewriting (17) as

$$
\phi_{1}^{\prime}\left(\hat{z}_{1}^{D}\right)=c_{1}+M_{1} D_{i}^{\prime}\left(M_{1} \hat{z}_{1}+M_{2} \bar{z}_{2}\right)+\frac{\alpha_{12} M_{1}}{1+\alpha_{11} M_{1}} M_{2} D_{2}^{\prime}\left(M_{1} \hat{z}_{1}+M_{2} \bar{z}_{2}\right) .
$$

This is exactly the same as before only rewritten such that the last part of the equation captures the marginal damage experienced in country 2 as the result of a consumption change in country 2 . It shows that the damage in country 2 is internalised to the degree defined by the coefficient $\frac{\alpha_{12} M_{1}}{1+\alpha_{11} M_{1}}$. If this coefficient is equal to one, the Domestic Planner will fully internalise global damage, the same as the Global Planner would determine under standard theory without altruism. We know that this is the case if

$$
\left(\alpha_{12}-\alpha_{11}\right) M_{1}=1 .
$$

From this we see immediately that the condition requires that $\alpha_{12}>\alpha_{11}$, which means it requires that the level of altruistic concern for the other country is larger than it is for their

18 Assuming non-linear damage functions. 
own country. Furthermore, we can also rewrite this condition as

$$
\frac{1+\alpha_{11} M_{1}}{\alpha_{12} M_{2}}=\frac{M_{1}}{M_{2}} \text {. }
$$

We know that the left hand side of (19) is greater than one due to the constraint imposed earlier on the total level of altruistic concern relative to the private utility of consumption $\left(\alpha_{11} M_{1}+\alpha_{12} M_{2} \leq 1\right)$. Therefore for the condition to hold, we require $M_{1}$ to be larger than $M_{2}$ and in such a way that the ratio between the sum of the concern for the individual's private utility and the welfare of all others in the same country, and the concern for individuals in the other country, is the same as the ratio between the population sizes of the two countries. Intuitively this means that the size of country 2 has to be sufficiently small and the level of altruistic concern for the other country be sufficiently larger than the concern for the domestic welfare in order for the altruistic concern to have enough weight in the domestic social welfare function that it fully internalises the damage of country 2 . In the $n$-country case this would have to hold for each of the other countries and for this to be consistent with the restriction in (13), country 1 has to become larger and larger relative to all other countries the more countries there are. ${ }^{19}$ It is noteworthy that it is counter-intuitive that this condition would actually hold, since it is reasonable to expect that the level of altruistic concern for the welfare in another country is not greater than the level of concern for welfare in their own country.

We have already determined earlier that equilibrium consumption in country 1 will decrease with an increase in their level of altruistic concern for country 2 (i.e. $\frac{\partial \hat{z}_{1}^{D}}{\partial \alpha_{12}}<0$ ), and that equilibrium consumption in country 1 will increase with an increase in the level of altruistic concern for their own country (i.e. $\frac{\partial \hat{z}_{1}^{D}}{\partial \alpha_{11}}>0$ ). We have already established that it is the relative levels of altruism that matter. Therefore let us define the following parameters representing the level of altruistic concern by individuals in country 1 and country 2 for the other country relative to the concern for their country and the direct utility from consumption respectively:

$$
A_{1}^{D}=\frac{\alpha_{12} M_{1}}{1+\alpha_{11} M_{1}}, \quad A_{2}^{D}=\frac{\alpha_{21} M_{2}}{1+\alpha_{22} M_{2}} .
$$

It is these parameters that dictate to what degree the damage in another country is internalised. Using them, we can derive that

$$
\begin{gathered}
\frac{\partial \hat{z}_{1}^{D}}{\partial A_{1}^{D}}=\frac{1}{\left|\mathbf{H}^{D}\right|}\left\{M_{2} D_{2}^{\prime}\left[\phi_{2}^{\prime \prime}(.)-A_{2}^{D} M_{1} M_{2} D_{1}^{\prime \prime}(.)-M_{2}^{2} D_{2}^{\prime \prime}(.)\right]\right\}<0 \\
\text { where }\left|\mathbf{H}^{D}\right|=\phi_{1}^{\prime \prime}(.)\left[\phi_{2}^{\prime \prime}(.)-A_{2}^{D} M_{1} M_{2} D_{1}^{\prime \prime}(.)-M_{2}^{2} D_{2}^{\prime \prime}(.)\right] \\
-\phi_{2}^{\prime \prime}(.)\left[M_{1}^{2} D_{1}^{\prime \prime}(.)+A_{1}^{D} M_{1} M_{2} D_{2}^{\prime \prime}(.)\right]>0 .
\end{gathered}
$$

As we would expect, consumption in country 1 decreases as the relative level of altruistic concern for country 2 increases. However, equilibrium consumption in country 1 also depends on consumption in country 2 . Since we know that an increase in $A_{2}^{D}$ will decrease consumption in country 2 , we can deduce that this means that consumption in country 1 will increase. Formally this is shown by

$$
\frac{\partial \hat{z}_{1}^{D}}{\partial A_{2}^{D}}=\frac{1}{\left|\mathbf{H}^{D}\right|}\left\{M_{1} D_{1}^{\prime}\left[M_{1} M_{2} D_{1}^{\prime \prime}(.)+A_{1}^{D} M_{2}^{2} D_{2}^{\prime \prime}(.)\right]\right\}>0 .
$$

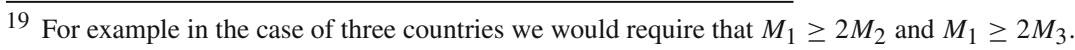


This shows that consumption in country 1 increases as the relative level of altruistic concern by individuals in country 2 for country 1 increases. This is consistent with our earlier findings. Note that $A_{2}^{D}$ does not affect the consumption choice of country 1 directly but only through the change in the consumption level for country 2 . Therefore we can also express (22) as

$$
\frac{\partial \hat{z}_{1}^{D}}{\partial A_{2}^{D}}=\frac{\partial \hat{z}_{2}^{D}}{\partial A_{2}^{D}} \frac{\partial \hat{z}_{1}^{D}}{\partial \hat{z}_{2}^{D}}>0
$$

This illustrates that as $A_{2}^{D}$ increases, consumption in country 2 decreases in line with the equivalent of (21) for country 2 . And since consumption in country 2 decreases, consumption in country 1 increases.

We can now turn to see how the socially optimum level from the perspective of a Global Planner is affected by the presence of Pure Altruism.

\subsection{Global Social Planner}

As before, the Global Planner simultaneously maximises the joint welfare functions of all $n$ countries. Therefore total global welfare is given by

$$
W_{T}\left(z_{1}, \ldots, z_{n}\right)=\sum_{i=1}^{n}\left\{M_{i}\left[\left(1+\alpha_{i i} M_{i}\right) S_{i}(.)+\sum_{j \neq i}\left[\alpha_{i j} M_{j} S_{j}(.)\right]\right]\right\} .
$$

Taking the first order condition with respect to $z_{i}$, it is then straightforward to derive that globally socially optimal consumption of the dirty good in country $i$ is characterised by

$$
\begin{aligned}
\phi_{i}^{\prime}\left(\hat{z}_{i}^{G}\right)= & c_{i}+M_{i} D_{i}^{\prime}\left(M_{1} \hat{z}_{1}^{G}+\cdots+M_{n} \hat{z}_{n}^{G}\right) \\
& +\sum_{j \neq i}\left\{\frac{1+\sum_{h=1}^{n}\left[\alpha_{h j} M_{h}\right]}{1+\sum_{h=1}^{n}\left[\alpha_{h i} M_{h}\right]} M_{j} D_{j}^{\prime}\left(M_{1} \hat{z}_{1}^{G}+\cdots+M_{n} \hat{z}_{n}^{G}\right)\right\} \quad \forall \quad 1 \leq i \leq n .
\end{aligned}
$$

The above shows that - just as in the case of the Domestic Planner- the damage in country $i$ is fully internalised, but the degree to which damage in the other countries is internalised depends on the relative levels of altruistic concern. Although this relative level of altruism is different from the Domestic Planner case, it shows that it is by no means given that the Global Planner fully internalises global damage equally in each country. One may intuitively expect that for a Global Planner the degrees of altruistic concern would cancel out somehow and we would still arrive at the same global optimum as described under standard theory in (9). However, this is not the case and altruism clearly does matter. In order to get a better understanding of what exactly is going on, let us look at the simplified case of only two countries. Then the global optimum for country 1 is characterised by

$$
\phi_{1}^{\prime}\left(\hat{z}_{1}^{G}\right)=c_{1}+M_{1} D_{1}^{\prime}\left(M_{1} \hat{z}_{1}^{G}+M_{2} \hat{z}_{2}^{G}\right)+\frac{1+\alpha_{12} M_{1}+\alpha_{22} M_{2}}{1+\alpha_{11} M_{1}+\alpha_{21} M_{2}} M_{2} D_{2}^{\prime}\left(M_{1} \hat{z}_{1}^{G}+M_{2} \hat{z}_{2}^{G}\right) .
$$

The first point that is evident from (25) is that the degree to which damage in country 2 is internalised does not just depend on the relative level of altruistic concern in country 1 for their own country and country 2 (as is the case for the Domestic Planner), but now the combined levels of altruistic concern in both countries for country 2 relative to the combined levels of altruistic concern in both countries for country 1 drive the degree to which damage in country 2 is internalised. This is because the Global Planner maximises the joint global 
welfare function that also includes the effect of country 2 on country 1 , and their levels of altruistic concern. Indeed, it is straightforward to see that if in both countries the level of altruistic concern is at the same level for their own country as it is for the other country (or in other words $\alpha_{11}=\alpha_{12}$ and $\alpha_{22}=\alpha_{21}$ ), then the coefficient is equal to 1 , and the socially optimal level fully internalises global damage (i.e. $\phi_{1}^{\prime}\left(\hat{z}_{1}^{G}\right)=c_{1}+M_{T} D_{T}^{\prime}\left(M_{1} \hat{z}_{1}^{G}+M_{2} \hat{z}_{2}^{G}\right)$ ). And of course it is also evident that in this case the socially optimal level in country 2 fully internalises damage in country 1 as well, and we have the same optimum as under standard theory without altruism. To generalise this to the $n$-country case we would require $\alpha_{i i}=\alpha_{i j}$ $\forall 1 \leq i, j \leq n$. But because the levels of altruistic concern may be different for each country, and each of those parameters enters the global welfare function, the global optimum with Pure Altruism may very well be different from the standard theory result where each country internalises global damage to the same degree. Also note that even if there is only altruistic concern by individuals for their own countries $\left(\alpha_{i j}=0 \forall 1 \leq i, j \leq n, i \neq j\right)$ then the global optimum is still not the same as under standard theory unless the degree of altruistic concern within each country is also the same.

However, it is not strictly necessary to have exactly the same levels of altruistic concern for the other countries as for their own country in order for the coefficient for the marginal damage of the other country to be 1 . More generally we can see that the marginal damage in the other country will be fully internalised if

$$
\frac{\alpha_{11}-\alpha_{12}}{\alpha_{22}-\alpha_{21}}=\frac{M_{2}}{M_{1}}
$$

Let us refer to the difference between the altruistic concern for their own country and the concern for the other country as the 'additional domestic altruism' (e.g. $\alpha_{11}-\alpha_{12}$ ), assuming for simplicity that the altruistic concern for their own country is larger than for the other country. Then we can see from the above that if the relative level of additional domestic altruism in both countries is equal to the inverse of the relative size of the two countries the global optimum will internalise global damage equally for each country. In the $n$-country case this requirement becomes a little more complicated. In order for the damage of country $j$ to be fully internalised in the socially optimum consumption of country $i$ we would require the population weighted additional domestic altruism in country $i$ to be equal to the sum of the population weighted additional altruism for country $j$ relative to country $i$ by all other countries. Specifically we would require

$$
\left(\alpha_{i i}-\alpha_{i j}\right) M_{i}=\sum_{h \neq i}\left\{\left(\alpha_{h j}-\alpha_{h i}\right) M_{h}\right\} \quad \forall 1 \leq i, j \leq n, \quad i \neq j .
$$

The above condition is necessary for the global optimum to equally internalise global damage in each country. However, the key intuition behind a global social optimum including degrees of Pure Altruism in the welfare function is that one country may internalise more of the damage due to the relative levels of altruism compared to another country. Indeed, if the population weighted sum of the altruistic concern for country $j$ across all countries is greater than the sum of population weighted altruistic concern for country $i$, then the social optimum for country $i$ would imply internalising more than global marginal damage. Of course in turn country $j$ 's optimal consumption level would internalise less than global marginal damage. If, in a two-country example, country 1 has a large amount of altruistic concern for the welfare of country 2 but country 2 has a low level of altruistic concern for the welfare of individuals in country 1 but a high level of concern for the welfare of their own country, then the global welfare function will put more weight on the damage experienced in country 2 than a Global Planner would do under standard theory. Altruistic concern of individuals in 
country 1 for country 2 means that the individuals in country 1 do not just experience the damage directly, but they also suffer to some degree the damage the individuals in country 2 experience. Therefore they are affected more by the externality than they would be without altruism.

Result 5 In a multi-country setting the socially optimal level of consumption from a Global Planner's perspective is driven by the relative levels of altruistic concern. If, in each country, the levels of altruistic concern for the domestic welfare is the same as the level of altruistic concern for welfare in all other countries, then the social optimum internalises the global damage equally across each country. However, if the relative levels of altruistic concern for a particular country by other countries are large, the welfare of that country-and therefore the damage function of that country - will carry more weight in determining the global optimum.

Comparing both the optimal consumption levels under the Domestic Planner with that of the Global Planner, we can further determine that as long as the level of altruistic concern for domestic welfare is larger than the level of concern for the welfare in other countries (i.e. $\alpha_{i i}>\alpha_{i j} \forall 1 \leq i, j \leq n, i \neq j$ ), then the global social optimum will lead to a lower consumption level of the dirty good compared to the domestic social optimum. This makes intuitive sense since the Global Planner would, on average, internalise more of the global effect of the externality than a Domestic Planner could achieve through the effect of altruism alone.

Finally, similar to the Domestic Planner case, let us look at how the relative levels of altruism for each country affect the global optimum. To do that, we define the following parameters representing the total level of altruism for one country and the direct utility of consumption relative to the total level of altruism for the other country and the direct utility from consumption. These are

$$
A_{1}^{G}=\frac{1+\alpha_{12} M_{1}+\alpha_{22} M_{2}}{1+\alpha_{11} M_{1}+\alpha_{21} M_{2}}, \quad A_{2}^{G}=\frac{1+\alpha_{11} M_{1}+\alpha_{21} M_{2}}{1+\alpha_{12} M_{1}+\alpha_{22} M_{2}} .
$$

Using the above it easy to show that

$$
\frac{\partial \hat{z}_{1}^{G}}{\partial A_{1}^{G}}<0 \quad \text { and } \quad \frac{\partial \hat{z}_{1}^{G}}{\partial A_{2}^{G}}>0 .
$$

As we would expect, if the level of altruistic concern for country 2 (by either country) increases relative to the altruistic concern for country 1, the optimal consumption level in country 1 decreases, because then the welfare of country 2 has more weight in the global welfare function compared to country 1 . Similarly, if the altruistic concern for country 1 increases relative to the altruistic concern for country 2 , the optimal consumption level for country 1 increases.

We have now completed the analysis of the non-cooperative and cooperative equilibria in the presence of Pure Altruism. The next step is to see how the optimal tax to induce this optimal behaviour under both the Domestic Planner and the Global Planner has changed compared to standard theory.

\subsection{Optimal Tax}

We have seen in Sect. 4.1 that adding Pure Altruism to the individual's utility function does not alter individual behaviour due to the atomistic nature of the consumption decision in this model. However, we have also determined that altruistic concern for other countries does 
influence the socially optimal level of consumption, whether this is the level determined through the non-cooperative equilibrium as a result of Domestic Planners or the global optimum determined by the cooperative solution of the Global Planner. This is a key difference compared to the results under standard theory as well as compared to a single country model with Pure Altruism.

Yet, because individual behaviour is unaffected by their altruism, under both solutions discussed every individual in country $i$ still consumes the same amount of the dirty good and we can induce this solution through a tax on the dirty good. For the Domestic Planner, it is straightforward to derive that the required tax on the dirty good is

$$
\begin{aligned}
\hat{t}_{i}^{D}= & M_{i} D_{i}^{\prime}\left(M_{i} \hat{z}_{i}^{D}+M_{-i} \bar{z}_{-i}\right) \\
& +\frac{M_{i}}{1+\alpha_{i i} M_{i}} \sum_{j \neq i} \alpha_{i j} M_{j} D_{j}^{\prime}\left(M_{i} \hat{z}_{i}^{D}+M_{-i} \bar{z}_{-i}\right) \quad \forall \quad 1 \leq i \leq n .
\end{aligned}
$$

As under standard theory, this tax may be different for each country depending on their damage function. In addition, it is now also a function of the altruistic concern individuals in this country may have. However, we also see now that, unlike under standard theory, to achieve the global optimum we cannot impose the same tax in every country and need to have a different tax for each country depending on the relative levels of altruistic concern. As such the required tax for country $i$ to induce the global optimum is

$$
\begin{aligned}
\hat{t}_{i}^{G}= & M_{i} D_{i}^{\prime}\left(M_{i} \hat{z}_{i}^{G}+M_{-i} \hat{z}_{-i}^{G}\right) \\
& +\sum_{j \neq i}\left\{\frac{1+\sum_{h=1}^{n}\left[\alpha_{h j} M_{h}\right]}{1+\sum_{h=1}^{n}\left[\alpha_{h i} M_{h}\right]} M_{j} D_{j}^{\prime}\left(M_{i} \hat{z}_{i}^{G}+M_{-i} \hat{z}_{-i}^{G}\right)\right\} \quad \forall \quad 1 \leq i \leq n .
\end{aligned}
$$

As already discussed in the previous section, the required tax on the dirty good would only be the same for each country if for each country the degree of altruistic concern for their own country is the same as that for every other country. Even if that were the case, it means that inducing the global optimum requires significantly more information about individuals and the damage caused in individual countries; knowledge about global damage is not sufficient anymore. Not only does the Global Planner require information about the various levels of altruistic concern, but also about the different damage functions for each country. This is important because with altruistic concern, even if a cooperative solution can be achieved, it is not straightforward for policy makers to determine the Pigovian tax for each country.

Result 6 With Pure Altruism in a multi-country setting the cooperative global (first-best) solution can no longer be induced by a single global tax on the dirty good unless in each country the levels of altruistic concern for the domestic welfare are the same as the concern for welfare in all other countries.

\section{The Effect of Population Sizes}

Throughout the analysis it has been evident that the marginal damage experienced is a function of the population sizes. This section aims to show how the different equilibria are affected when a population size changes. As before this will first be done under standard theory and then for the case with Pure Altruism. 


\subsection{Standard Theory}

\section{Domestic Social Planner}

The damage function is non-linear in total emissions $E$, and therefore, as we have already noted earlier, marginal damage is a function of the average consumption level in all other countries. Therefore (6) describes the reaction function leading to the Nash equilibrium. In order to explore the equilibrium level of consumption, let us now assume there are only two countries and each sets its socially optimal tax. Then the reaction function for country 1 becomes

$$
\phi_{1}^{\prime}\left(\hat{z}_{1}^{D}\right)=c_{1}+M_{1} D_{1}^{\prime}\left(M_{1} \hat{z}_{1}^{D}+M_{2} \hat{z}_{2}^{D}\right) .
$$

We already know that consumption in country 1 depends on consumption in country 2 and vice versa. Specifically, we can determine that the degree to which optimal consumption in one country changes as the result of a consumption change in the other country is given by

$$
\frac{\partial \hat{z}_{1}^{D}}{\partial \hat{z}_{2}^{D}}=\frac{M_{1} M_{2} D_{1}^{\prime \prime}(.)}{\phi_{1}^{\prime \prime}(.)-M_{1}^{2} D_{1}^{\prime \prime}(.)}<0 \text { and } \frac{\partial \hat{z}_{2}^{D}}{\partial \hat{z}_{1}^{D}}=\frac{M_{1} M_{2} D_{2}^{\prime \prime}(.)}{\phi_{2}^{\prime \prime}(.)-M_{2}^{2} D_{2}^{\prime \prime}(.)}<0 \text {. }
$$

It makes intuitive sense that consumption in one country will decrease as consumption in the other country increases. This is because if consumption in one country increases this also increases marginal damage in the other country and therefore the social optimum under the Domestic Planner has to decrease in the other country. From this we can also determine the conditions in the two-country case that need to hold in order to have a unique and stable Nash Equilibrium where both countries consume positive amounts of the dirty good. For this we require $\left|\frac{\partial \hat{z}_{1}^{D}}{\partial \hat{z}_{2}^{D}}\right|<1$ and $\frac{\partial \hat{z}_{2}^{D}}{\partial \hat{z}_{1}^{D}} \mid<1 .{ }^{20}$ These conditions are

$$
M_{1}\left(M_{2}-M_{1}\right)<\frac{-\phi_{1}^{\prime \prime}(.)}{D_{1}^{\prime \prime}(.)} \text { and } M_{2}\left(M_{1}-M_{2}\right)<\frac{-\phi_{2}^{\prime \prime}(.)}{D_{2}^{\prime \prime}(.)} .
$$

Given one country is bigger than the other, then one of the two conditions will always hold. However, the other is more restrictive and essentially guarantees that one country is not too large compared to the other. Depending on the damage function and the total population, it is possible that one country is so large that the marginal damage increases to a level where it can no longer consume a positive amount of the dirty good given the optimal level of consumption in the other country with a smaller population and lower marginal damage.

Next, assuming that a stable and unique equilibrium exists, let us analyse how changes in the population size affect the non-cooperative equilibrium. We can derive from (30) and the equivalent for country 2 that

$$
\frac{\partial \hat{z}_{1}^{D}}{\partial M_{1}}=\frac{\phi_{2}^{\prime \prime}(.)\left[D_{1}^{\prime}(.)+M_{1} \hat{z}_{1}^{D} D_{1}^{\prime \prime}(.)\right]-M_{2}^{2} D_{1}^{\prime}(.) D_{2}^{\prime \prime}(.)}{\phi_{1}^{\prime \prime}(.) \phi_{2}^{\prime \prime}(.)-\phi_{2}^{\prime \prime}(.) M_{1}^{2} D_{1}^{\prime \prime}(.)-\phi_{1}^{\prime \prime}(.) M_{2}^{2} D_{2}^{\prime \prime}(.)}<0 .
$$

Therefore an increase in the population size of country 1 leads to lower consumption of the dirty good in country 1 under the Domestic Planner. This makes intuitive sense as an increase in population leads to an increase in marginal damage which has to be offset by lower consumption levels. However, since the Domestic Planner has to take account of the emissions generated in other countries it is also important to explore how consumption in

20 These are the standard conditions for a unique and stable Nash equilibrium in a Cournot duopoly with linear reaction functions. 
other countries might change with an increase in the population of country 1 . Consumption in country 2 will be affected by the total emissions in country 1, and these are of course a function of the size of country 1 as well as the level of consumption of the dirty good in country 1 . Yet it is not definitive whether consumption in country 2 will increase or decrease. Specifically we find that

$$
\frac{\partial \hat{z}_{2}^{D}}{\partial M_{1}}=\frac{M_{2} D_{2}^{\prime \prime}(.)\left[\phi_{1}^{\prime \prime}(.) \hat{z}_{1}^{D}+M_{1} D_{1}^{\prime}(.)\right]}{\phi_{1}^{\prime \prime}(.) \phi_{2}^{\prime \prime}(.)-\phi_{2}^{\prime \prime}(.) M_{1}^{2} D_{1}^{\prime \prime}(.)-\phi_{1}^{\prime \prime}(.) M_{2}^{2} D_{2}^{\prime \prime}(.)}>0 \quad \text { if } \quad \hat{z}_{1}^{D}<\frac{M_{1} D_{1}^{\prime}(.)}{-\phi_{1}^{\prime \prime}(.)} .
$$

The above shows that consumption in country 2 will increase as a result of a population increase in country 1 if consumption in country 1 is less than the ratio between the marginal damage experienced in country 1 and the rate at which the marginal private gross benefit derived from consumption of the dirty good changes for individuals in country 1 . There are two effects driving this. First, an increase in $M_{1}$ increases the marginal damage for country 2 and, ceteris paribus, works towards reducing consumption of the dirty good in country 2 . However, because the increase in $M_{1}$ will reduce consumption of the dirty good in country 1 , this reduction may offset the effect on $D_{2}^{\prime}$ (.) sufficiently to allow country 2 to actually increase its consumption of the dirty good. From the condition given in (34) we see that this is the case if consumption in country 1 is sufficiently low. The lower consumption in country 1 , the less an increase in their population will affect marginal damage of country 2 and therefore the more likely it is that the resulting decrease in consumption in country 1 is sufficient to allow country 2 to increase its consumption of the dirty good.

\section{Global Social Planner}

When considering the Global Planner it makes intuitive sense that if the population in any of the countries increases, this leads to an increase in global marginal damage and therefore consumption of the dirty good by each individual in each country has to decrease under a global social optimum. Formally, in the two-country case, the change in consumption in country 1 as a result of the population increase in country 1 is given by

$$
\frac{\partial \hat{z}_{1}^{G}}{\partial M_{1}}=\frac{\phi_{2}^{\prime \prime}(.)\left[D_{1}^{\prime}(.)+M_{1} \hat{z}_{1}^{G} D_{1}^{\prime \prime}(.)+M_{2} \hat{z}_{1}^{G} D_{2}^{\prime \prime}(.)\right]}{\phi_{1}^{\prime \prime}(.)\left[\phi_{2}^{\prime \prime}(.)-M_{1} M_{2} D_{1}^{\prime \prime}(.)-M_{2}^{2} D_{2}^{\prime \prime}(.)\right]-\phi_{2}^{\prime \prime}(.)\left[M_{1}^{2} D_{1}^{\prime \prime}(.)+M_{1} M_{2} D_{2}^{\prime \prime}(.)\right]}<0,
$$

and similarly it can be shown that $\frac{\partial \hat{z}_{2}^{G}}{\partial M_{1}}<0$. This also demonstrates that any differences in the amount of change between the two countries as a result of the population increase in country 1 is only driven by the private preferences over the dirty good. This is consistent with the earlier finding that in a global equilibrium differences in consumption are only caused by differences in the private benefit from consumption of the dirty good as well as differences in the cost of production. ${ }^{21}$

\section{Comparison of the Domestic and Global Planner}

In general it is intuitive that average consumption across the two countries will always be lower under the global equilibrium compared to the domestic equilibrium because the Global Planner internalises more damage than each of the Domestic Planners. However, it is

21 Since the cost of production is assumed to be a constant, it has no impact on the degree to which optimal consumption changes as the result of a population increase. 
theoretically possible that, for example, consumption in country 1 could be higher under the Global Planner than under the Domestic Planner. This would be the case if the size of country 1 is sufficiently large relative to country 2 such that the domestic equilibrium would have a very low level of consumption in country 1 and a comparatively high level in country 2 . The Global Planner's equilibrium would then redistribute this imbalance and allow country 1 to consume more, but of course require country 2 to consume less. This is because a large country 1 internalises its own experienced damage fully (although it ignores its effect on the other countries) while a global optimum equally shares the burden of global emissions (which are disproportionately caused by country 1 in this example). Note that this may be different if country 1 has a 'lower' damage function compared to country 2 .

Formally, using the two-country setup and assuming for simplicity that both countries have the same damage function, the requirement for $\hat{z}_{1}^{G}<\hat{z}_{1}^{D}$ is

$$
\frac{M_{1}}{M_{1}+M_{2}}<\frac{D^{\prime}\left(M_{1} \hat{z}_{1}^{G}+M_{2} \hat{z}_{2}^{G}\right)}{D^{\prime}\left(M_{1} \hat{z}_{1}^{D}+M_{2} \hat{z}_{2}^{D}\right)} .
$$

After having established how the equilibria react to changes in the population size under standard theory, let us know explore the same in the case of Pure Altruism.

\subsection{Pure Altruism}

\section{Domestic Social Planner}

Again turning to the case of only two countries, we find that the change in the domestic optimum in country 1 as a result of the population increase in country 1 is given by

$$
\begin{aligned}
\frac{\partial \hat{z}_{1}^{D}}{\partial M_{1}}= & \frac{1}{\left|\mathbf{H}^{D}\right|}\left\{\phi_{2}^{\prime \prime}(.)\left[D_{1}^{\prime}(.)+M_{1} z_{1} D_{1}^{\prime \prime}(.)+A_{1}^{D} M_{2} z_{1} D_{2}^{\prime \prime}(.)\right]\right. \\
& \left.-\left(1-A_{1}^{D} A_{2}^{D}\right)\left[M_{2}^{2} D_{1}^{\prime}(.) D_{2}^{\prime \prime}(.)\right]\right\}<0,
\end{aligned}
$$

Since we know that $A_{1}^{D} A_{2}^{D}<1$ from the restriction put on the total level of altruistic concern we also know that, as in the case without altruism, an increase in consumption in country 1 leads to a decrease in domestically optimal consumption of the dirty good in country 1 . Furthermore, the resulting change in consumption in country 2 is given by

$$
\begin{aligned}
\frac{\partial \hat{z}_{2}^{D}}{\partial M_{1}}= & \frac{1}{\left|\mathbf{H}^{D}\right|}\left\{\phi_{1}^{\prime \prime}(.)\left[A_{2}^{D} D_{1}^{\prime}(.)+A_{2}^{D} M_{1} z_{1} D_{1}^{\prime \prime}(.)+M_{2} z_{1} D_{2}^{\prime \prime}(.)\right]\right. \\
& \left.-\left(1-A_{1}^{D} A_{2}^{D}\right)\left[M_{1} M_{2} D_{1}^{\prime}(.) D_{2}^{\prime \prime}(.)\right]\right\} .
\end{aligned}
$$

Similar to the findings under standard theory, it is not clear whether consumption in country 2 will increase or decrease as a result of the population increase in country 1 . The condition for $\frac{\partial \hat{z}_{2}^{D}}{\partial M_{1}}>0$ is given by

$$
-\phi_{1}^{\prime \prime}(.)<\frac{\left(1-A_{1}^{D} A_{2}^{D}\right)\left[M_{1} M_{2} D_{1}^{\prime}(.) D_{2}^{\prime \prime}(.)\right]}{A_{2}^{D} D_{1}^{\prime}(.)+A_{2}^{D} M_{1} z_{1} D_{1}^{\prime \prime}(.)+M_{2} z_{1} D_{2}^{\prime \prime}(.)},
$$

where of course the left hand side is a positive value. While this condition is not straightforward to interpret, the intuition is the same as for the case without altruism. If country 1 
is sufficiently large or the marginal damage in country 1 is sufficiently high relative to the private benefit of consumption in country 1 and the size and marginal damage in country 2 , the decrease in consumption in country 1 can be such that country 2 could actually increase consumption of the dirty good under a Domestic Planner. Of course the levels of altruistic concern the two countries have for themselves and the other country influences how much a country changes its consumption of the dirty good. ${ }^{22}$

\section{Global Social Planner}

In the case of the global optimum, we find that the effect of a population increase in country 1 is captured by

$$
\begin{aligned}
& \frac{\partial \hat{z}_{1}^{G}}{\partial M_{1}}=\frac{1}{\left|\mathbf{H}^{G}\right|}\left\{\phi_{2}^{\prime \prime}(.)\left[D_{1}^{\prime}(.)+M_{1} z_{1} D_{1}^{\prime \prime}(.)+A_{1}^{G} M_{2} z_{1} D_{2}^{\prime \prime}(.)\right]\right. \\
& \left.-\left(1-A_{1}^{G} A_{2}^{G}\right)\left[M_{2}^{2} D_{1}^{\prime}(.) D_{2}^{\prime \prime}(.)\right]\right\}<0, \\
& \text { where }\left|\mathbf{H}^{G}\right|=\phi_{1}^{\prime \prime}(.)\left[\phi_{2}^{\prime \prime}(.)-A_{2}^{G} M_{1} M_{2} D_{1}^{\prime \prime}(.)-M_{2}^{2} D_{2}^{\prime \prime}(.)\right] \\
& \\
& \quad-\phi_{2}^{\prime \prime}(.)\left[M_{1}^{2} D_{1}^{\prime \prime}(.)+A_{1}^{G} M_{1} M_{2} D_{2}^{\prime \prime}(.)\right]>0 .
\end{aligned}
$$

Since $A_{1}^{G} A_{2}^{G}=1$ we can see that the second part of the numerator falls away. Note that the only differences between (40) and (37) are the altruism parameters $A^{D}$ and $A^{G}$. With regard to the impact of a change in $M_{1}$ on the global optimum for country 2 we find that

$$
\frac{\partial \hat{z}_{2}^{G}}{\partial M_{1}}=\frac{1}{\left|\mathbf{H}^{G}\right|}\left\{\phi_{1}^{\prime \prime}(.)\left[A_{2}^{G} D_{1}^{\prime}(.)+A_{2}^{G} M_{1} z_{1} D_{1}^{\prime \prime}(.)+M_{2} z_{1} D_{2}^{\prime \prime}(.)\right]\right\}<0 .
$$

Therefore optimal consumption falls in both countries as a result of a population increase in either country. This is consistent with Global Planner results under standard theory shown in Sect. 5.1.

\section{Concluding Remarks}

This paper has shown that while individual behaviour is unaffected by altruism in the multicountry setting, meaning individuals will free-ride in the absence of a tax on the dirty good regardless of their level of altruistic concern for others, determining the optimal level of consumption of the dirty good for both a non-cooperative and cooperative welfare maximising solution, as well as determining the right tax to induce that level, becomes more complex. At the same time, individual behaviour is unaffected due to the atomistic nature of the consumption decision. Therefore no matter how much they may care about the welfare of others, in their country or another, their consumption choice has no impact on global emissions, and thus the chosen consumption level is only determined by the private marginal benefit and cost of consumption.

22 Also note that if both $A_{1}^{D}=0$ and $A_{2}^{D}=0$, then the condition described in (39) reduces to that shown in (34). 
Given the global nature of climate change, non-cooperating governments might maximise domestic welfare, taking consumption in other countries as given. However the social optimum is determined by the global cooperative solution where global welfare is maximised for each country simultaneously. With or without altruism, the global optimum implies lower average consumption compared to non-cooperative solution. While individuals will free-ride on the damage their consumption causes, governments maximising domestic welfare only will also free-ride on the damage caused to other countries. Under standard theory the Domestic Planner will only internalise domestic damage, while a Global Planner will internalise global damage completely and differences in optimal consumption are only caused by differences in private preferences and the cost of production of the dirty good. Therefore the global optimum can be induced by a single tax rate on the dirty good for everyone globally, equal to global marginal damage from the dirty good. This is a common result in the literature.

However, this paper has shown that if individuals exhibit altruistic concern for the utility of others, both the non-cooperative solution as well as the global optimum will change. If individuals exhibit altruistic concern for the welfare of other countries, then the Domestic planners' non-cooperative solution will internalise the damage caused to other countries depending on the level of altruistic concern for that country relative to the altruistic concern for their own country and their own private utility. Yet the Domestic Planner will never fully internalise global damage if there are more than two countries. Altruistic concern for other countries effectively increases the damage individuals experience as they will not just be affected by the damage they experience directly, but also the damage others experience. Consequently, even the Domestic Planner has to take account of damage caused to other countries. The key result, however, is that the global optimum is affected by the existence of altruistic concern for the same reasons. Effectively altruism means that global damage is now not the simple sum of all the individual damage functions but the weighting has to be adjusted for the damage experienced via altruistic concern for others. This depends on the relative levels of altruistic concern each country has for their own country and for other countries, and means that unless for each country the altruistic concern for their own country is the same as for all other countries, the global optimum will be different from standard theory. From this it also follows that although altruistic concern leads the Domestic Planner to internalise some of the damage, the gap between the non-cooperative solution and the global optimum may not narrow. Furthermore, this paper has shown that with altruism the global optimum can no longer be achieved by a single tax equal global marginal damage, but it has to be adjusted for each country depending on the levels of altruistic concern. This significantly increases the information policy makers require to set the right tax on emissions even if a global cooperative solution could be achieved.

Acknowledgements The author would like to thank David Ulph, two very constructive referees, as well as participants at the 21st Annual EAERE Conference in Helsinki, for their helpful comments and suggestions. Funding from the Economic and Social Research Council (Grant No. ES/J500136/1) is gratefully acknowledged.

Open Access This article is distributed under the terms of the Creative Commons Attribution 4.0 International License (http://creativecommons.org/licenses/by/4.0/), which permits unrestricted use, distribution, and reproduction in any medium, provided you give appropriate credit to the original author(s) and the source, provide a link to the Creative Commons license, and indicate if changes were made. 


\section{References}

Altemeyer-Bartscher M, Rübbelke D, Sheshinski E (2010) Environmental protection and the private provision of international public goods. Economica 77(308):775-784

Altemeyer-Bartscher M, Markandya A, Rübbelke D (2011) The private provision of international impure public goods: the case of climate policy. Basque Centre for Climate Change (BC3), Bilbao

Altemeyer-Bartscher M, Markandya A, Rübbelke D (2014) International side-payments to improve global public good provision when transfers are refinanced through a tax on local and global externalities. Int Econ J 28(1):71-93

Archibald GC, Donaldson D (1976) Non-paternalism and the basic theorems of welfare economics. Can J Econ 9(3):492-507

Aronsson T, Blomquist S (2003) Optimal taxation, global externalities and labor mobility. J Public Econ $87: 2749-2764$

Aronsson T, Johansson-Stenman O (2014) When Samuelson met Veblen abroad: national and global public good provision when social comparisons matter. Economica 81(322):224-243

Aronsson T, Johansson-Stenman O (2015) Keeping up with the Joneses, the Smiths and the Tanakas: on international tax coordination and social comparisons. J Public Econ 131:71-86

Aronsson T, Löfgren KG (2001) Green accounting and green taxes in the global economy. In: Folmer H, Gabel HL, Gerking S, Rose A (eds) Frontiers of environmental economics, chap 1. Edward Elgar, Cheltenham, pp 12-35

Barrett S (1990) The problem of global environmental protection. Oxf Rev Econ Policy 6(1):68-79

Barrett S (1994) Self-enforcing international environmental agreements. Oxf Econ Pap 46:878-894

Becker GS (1974) A theory of social interactions. J Polit Econ 82(6):1063-1093

Becker GS (1981) Altruism in the family and selfishness in the market place. Economica 48(189):1-15

Bierbrauer F, Brett C, Weymark JA (2013) Strategic nonlinear income tax competition with perfect labor mobility. Games Econ Behav 82:292-311

Buchholz W, Sandler T (2017) Successful leadership in global public good provision: incorporating behavioural approaches. Environ Resour Econ 67(3):591-607

Cornes R, Sandler T (1984) Easy riders, joint production, and public goods. Econ J 94(375):580-598

Daube M, Ulph D (2016) Moral behaviour, altruism and environmental policy. Environ Resour Econ 63(2):505522

Hammond PJ (1987) Altruism. In: Eatwell J, Milgate M, Newman P (eds) The new Palgrave: a dictionary of economics, 1st edn. Palgrave Macmillan, Basingstoke

Johansson O (1997) Optimal Pigovian taxes under altruism. Land Econ 73(3):297-308

Keen M, Konrad KA (2013) The theory of international tax competition and coordination. In: Auerbach A, Chetty R, Feldstein M, Saez E (eds) Handbook of public economics, vol 5. Elsevier, Amsterdam, pp 257-328

Markandya A, Rübbelke D (2004) Ancillary benefits of climate policy. J Econ Stat 224(4):488-503

Markandya A, Rübbelke D (2012) Impure public technologies and environmental policy. J Econ Stud 39(2):128-143

Nordhaus WD (2006) After Kyoto: alternative mechanisms to control global warming. Am Econ Rev 96(2):3134

Pittel K, Rübbelke D (2017) Thinking local but acting global? The interplay between local and global internalization of externalities. In: Buchholz W, Rübbelke D (eds) The theory of externalities and public goods. Springer, Berlin, pp 271-297

Tahvonen O (1995) International $\mathrm{CO}_{2}$ taxation and the dynamics of fossil fuel markets. Int Tax Public Finance 2(2):261-278

van der Ploeg F, de Zeeuw AJ (1992) International aspects of pollution control. Environ Resour Econ 2(2):117139 